\title{
An Estimation of Electromagnetic Field Exposure from Cellular Mobile Base Station Towers in Densely Populated Residential Areas
}

\author{
Amar Renke \\ KIT's College of Engineering, Kolhapur \\ Maharashtra, India
}

\author{
Mahesh Chavan \\ KIT's College of Engineering, Kolhapur \\ Maharashtra, India
}

\begin{abstract}
To increase the coverage area there is tremendous growth in cellular antenna installations on mobile towers, this increases the electromagnetic field exposure in nearby areas. This work presents measurements taken near the cellular mobile towers which are situated in densely populated urban areas in India. Measurements were conducted at distances ranging from $10 \mathrm{~m}$ to $150 \mathrm{~m}$ at height $1.5 \mathrm{~m}$ and it is along the radiating direction of the antenna using a 3 axis field strength meter KM 195 to obtain power densities and electric field intensities. It was observed that most of the cellular base station antenna sites following the Indian guidelines for cellular phone radiation measurements. The average power density noted is 3479.65 $\mu \mathrm{W} / \mathrm{m}^{2}$. A total $80 \%$ of the power densities increase beyond $500 \mu \mathrm{W} / \mathrm{m}^{2}$. The amplitude of electromagnetic field exposure (EMF) depends on distance, height of base station tower, number of antennas on base station tower and direction. In densely populated residential areas the line of site distance available was up to $100 \mathrm{~m}$ and thereafter non line of site distance exists. It is observed that line of site power density was greater than non line of site power density. The results shows that, especially in some places near the cellular base stations the power densities were more and at some other places densities were too low, it is found that there was drastic change in power density and electric field intensity everyday and by measuring the general electromagnetic field exposure one can provide this data to the agencies who were control the electromagnetic field exposure and minimize the undesirable health effects.
\end{abstract}

\section{General Terms}

General electromagnetic field exposure, Residential field exposure, Electromagnetic radiation etc.

\section{Keywords}

Non-Ionizing radiation, Public concerns, Power density, Electric field intensity, densely populated, Occupational exposure.

\section{INTRODUCTION}

The cellular base stations are always radiating the electromagnetic field even when no one is using the mobile phone. As per the norms cellular base station transmitting antennas are supposed to away from residential areas by 100 to 300 meters depending upon the density of the population. In Kolhapur the cellular base stations (CBS) are mainly located in heart of the city. In cellular mobile communication directional antennas are more popular than Omni-directional as they cover the required section of the population. As told earlier, Sectored antennas are widely used because they cover different areas. There are two types of electromagnetic (EM) radiations, one is Ionizing radiation and second is NonIonizing radiation. Generally cellular base stations transmit Non-Ionizing type of EM radiation. That is it makes no ionization with our body molecules. But still there are some undesirable health effects of it. Therefore it is today's need to measure and analyze the radiation from cellular base stations (CBS) which are positioned in densely populated residential areas.

There is much awareness in developed foreign countries regarding non-ionizing radiation from CBS. The health effects like headaches, fatigue, dizziness and sleep disorders were experienced by the natives who are leaving near the CBS but there is no precise way to find that these effects are due to CBS radiation.

Only in very few cases EMF exposure level go beyond guideline value close to antenna sites. Therefore, very inadequate information is available on the EMF exposure from CBS radiation in densely populated residential.

The objective of this is paper is to measure residential exposure, perform statistical calculations, and compare results with various international standards. Measurements were performed at $10 \mathrm{~m}$ distance difference that is $10, \mathrm{~m}, 20 \mathrm{~m}, 30 \mathrm{~m}$, $40 \mathrm{~m}$ up to $150 \mathrm{~m}$ and in some cases it is up to $100 \mathrm{~m}$ in the region of cellular base station (CBS) antenna towers.

The radiating elements (antennas) are generally placed on CBS towers. The average antenna height is in between 100 feet to 200 feet. On the most of the cell phone towers the sectored directional antennas were mounted. People are exposed to EMF radiation due to major and minor of the antenna radiation pattern mostly due to major lobe radiation.

In India, the internet and telephone service providers such as BSNL, Reliance, Idea Cellular, Aircel and Bharti Airtel have installed thousands of CBS all the way through the country. In near future more and more CBS may be installed in urban areas of India..

Numerous factors will affect the amplitude of the EMF exposure measured from the CBS. Power density was more in major beam direction and low in minor lobes. The power densities vary in accordance with number of calls, time of call. Litovitz found that other EM sources such as TV and radio broadcast transmitters and electrical appliances, affects the power densities.

A number of organizations and various government authorities have created most useful guidelines to save general public and employees from the extreme RF radiation emitted from the CBS. Such international organizations are FCC, ICNIRP, NCRP, IEEE, NRPB and CENELEC [1-9] they 
developed general guidelines regarding EMF exposure from cellular base stations for the society and employees. Usually, the confines lay down by these authorities and organizations are similar. Table 1.0 shows general and occupational exposure limits.

Table 1. General and occupational exposure limits for frequency range 824-894 MHz

\begin{tabular}{|c|c|c|}
\hline Associations & Frequencies & Exposure Range \\
\hline NCRP, IEEE, FCC & $824-894 \mathrm{MHz}$ & $5.50-6.00 \mathrm{~W} / \mathrm{m}^{2}$ \\
\hline NRPB & $824-894 \mathrm{MHz}$ & $31.0-33.0 \mathrm{~W} / \mathrm{m}^{2}$ \\
\hline ICNIRP & $824-894 \mathrm{MHz}$ & $4.40-4.50 \mathrm{~W} / \mathrm{m}^{2}$ \\
\hline \multicolumn{3}{|c|}{ The working exposure limit } \\
\hline NCRP, IEEE, FCC & $824-894 \mathrm{MHz}$ & $28-30 \mathrm{~W} / \mathrm{m}^{2}$ \\
\hline NRPB & $824-894 \mathrm{MHz}$ & $31-33 \mathrm{~W} / \mathrm{m}^{2}$ \\
\hline ICNIRP & $824-894 \mathrm{MHz}$ & $21.8-22.4 \mathrm{~W} / \mathrm{m}$ \\
\hline
\end{tabular}

In our country $900 \mathrm{MHz}$ and $1800 \mathrm{MHz}$ frequencies were used by Cellular mobile communication in India, the EMF exposure boundaries lay down by ICNIRP are 450 and 900 mw/ $/ \mathrm{cm}^{2}$, respectively. Most of the counties following the guidelines set created by IEEE and ICNIRP. Several studies are going on, on the topic adverse health effects due to the RF radiation from CBS $[15,16,19]$. Therefore, most of the developed countries have accepted hard rules to control the EMF exposure limits. For example, Salzburg, china, Poland, Italy, Russia, Switzerland and Austria has put the exposure limit as $0.1 \mathrm{~W} / \mathrm{m}^{2}$. This is hundred times lesser than the boundary lay down by ICNIRP and FCC, which is equal to 10 $\mathrm{W} / \mathrm{m}^{2}$. Table 2.0 shows the general and working exposure confines for frequency range 1850-1990 MHz.

Table 2. General and working exposure limits for frequency range $1850-1990 \mathrm{MHz}$

\begin{tabular}{|c|c|c|}
\hline Organizations & $\begin{array}{c}\text { Frequency } \\
\text { range }\end{array}$ & $\begin{array}{c}\text { General } \\
\text { Exposure } \\
\text { limit }\end{array}$ \\
\hline FCC and NCRP & $\begin{array}{c}1850-1990 \\
\mathrm{MHz}\end{array}$ & $10 \mathrm{~W} / \mathrm{m}^{2}$ \\
\hline $\begin{array}{c}\text { NPRB, IEEE, } \\
\text { ICNIRP }\end{array}$ & $\begin{array}{c}1850-1990 \\
\mathrm{MHz}\end{array}$ & $\begin{array}{c}10-15,7.5-10 \\
\text { and } 92-100 \\
\mathrm{~W} / \mathrm{m}^{2}\end{array}$ \\
\hline \multicolumn{2}{|c|}{ The working exposure limit } \\
\hline NCRP and FCC & $\begin{array}{c}1850-1990 \\
\mathrm{MHz}\end{array}$ & $50 \mathrm{~W} / \mathrm{m}^{2}$ \\
\hline NPRB, IEEE, & $\begin{array}{c}1850-1990 \\
\mathrm{MHz}\end{array}$ & $\begin{array}{c}50-73,37.5- \\
50 \text { and } 92-100 \\
\mathrm{~W} / \mathrm{m}^{2}\end{array}$ \\
\hline
\end{tabular}

The international organizations like ICNIRP,ARPSNA, NRPB and in India DoT has given the guidelines to the society and commercial organizations to transmit the EMF radiation up to certain level which is not harmful to the common people which are leaving surrounding the CBS. But in most of the cases or in metropolitan cities these organizations which are handling the base stations not following the radiation rules, also number of antennas mounted on the each tower they are varying in numbers. various studies related to EMF exposure from base stations mentioned different adverse health effects of RF radiation from CBS such as dizziness, headaches, fatigue, sleep disorders, irritability etc.

Thus, major European countries grant serious concern to the thermal effects due to the RF radiation from CBS. Some EMF exposure guidelines gives importance to various sensitive places such as schools, hospitals etc.

Mobile phone gives the exposure only during the communication period but CBS radiates Electromagnetic radiation 24 hours uninterruptedly in the surrounding area. CBS towers are mounted on building terrace in urban areas. As a result, study on the measurement of the power densities of the antennas from the cellular base stations is essential and important one. [11-14]. Measurements of EMF exposure at such places is useful in finding the EMF exposure of the common population and also check the EMF exposure level whether it is below the reference level or not. The next section explains the actual methodology of the general EMF field exposure from CBS.

\section{MATERIALS AND METHODS}

Nowadays the measurement of EMF exposure due to cellular base stations is essential to avoid the excessive radiation from base stations. Base stations were selected according to number of antennas mounted on the base station antenna sites and population around the tower from Kolhapur city.

The base stations are selected from densely populated areas from Kolhapur city. Locations of the base stations, height of antenna, and number of antennas on tower are the important parameters; generally all the base station towers are from densely populated areas and close to the residences. Measurements were completed using a 3 axis field strength meter KM 195.

EMF exposure is measured with the help of this instrument from $800 \mathrm{MHz}$ to $2.5 \mathrm{GHz}$. The meter covers entire cellular frequency band. Measurements were taken during the daytime from 8.00 a.m. to 4.00 p.m. All EMF measurements were taken on sunny days in February and March, 2015.

Measurements were repeated again and again, and then the power density is averaged. Initially the base station was selected for measurement of EMF exposure and then readings were noted after every one hour between $8 \mathrm{am}$ to $5 \mathrm{pm}$. to observe the variations in the power density. Measurements were started from the bottom of the CBS, and measured radiation from $10 \mathrm{~m}$ to $150 \mathrm{~m}$.

Measurements were taken in the increments of 10 meter distance i.e. $10 \mathrm{~m}, 20 \mathrm{~m}, 30 \mathrm{~m}, 40 \mathrm{~m}$, up to 150 meters. All measurements were performed on sunny days; power density and electric field intensity both are measured simultaneously at height approximately 1.5 meters. Some cellular base station towers are mounted on ground and some on rooftop of buildings. The average height of the cellular base station tower is around 100 feets. The height chosen for the measurement was $1.5 \mathrm{~m}$ because in India the average height of the people is somewhat around 5 feet.

From measurements it was observed that radiation power density is maximum in the major lobe direction of the transmitting antenna and less in minor lobes direction. The fluctuations in the power density and electric field intensity are more.

Here both line of sight and non line of sight of EMF exposure situations were studied. Average numbers of antennas installed on the cellular mobile towers were around fifteen. 
For electromagnetic field (EMF) exposure there are some reference levels set by international organizations such as ICNIRP, WHO, IEEE, FCC and ARPSNA etc. most of the countries follow the reference levels set by ICNIRP. Table 1.0 shows international exposure limits for $900 \mathrm{MHz}$.

These reference levels were revised in September 2012 by department of telecommunications (DoT) for frequencies 900, 1800 and 2100. Table 1.1 shows revised DoT norms for EMF exposure.

Table 1. International EMF radiation norms for mobile towers (BTS)[2,3]

\begin{tabular}{|l|l|}
\hline \multicolumn{2}{|c|}{ International Exposure limits for EMF (900 MHz) } \\
\hline $0.45 \mathrm{~W} / \mathrm{m}^{2}$ & Exposure limit in India \\
\hline $4.5 \mathrm{~W} / \mathrm{m}^{2}$ & ICNIRP and EU recommendation 1998 \\
\hline $6.0 \mathrm{~W} / \mathrm{m}^{2}$ & USA, Canada and Japan \\
\hline $2.0 \mathrm{~W} / \mathrm{m}^{2}$ & Exposure limit in Australia \\
\hline $1.1 \mathrm{~W} / \mathrm{m}^{2}$ & Exposure limit in Belgium \\
\hline $1.0 \mathrm{~W} / \mathrm{m}^{2}$ & Exposure limit in Italy, Israel \\
\hline $0.5 \mathrm{~W} / \mathrm{m}^{2}$ & Exposure limit in Auckland, New Zealand \\
\hline $0.45 \mathrm{~W} / \mathrm{m}^{2}$ & Exposure limit in Luxembourg \\
\hline $0.4 \mathrm{~W} / \mathrm{m}^{2}$ & Exposure limit in China \\
\hline $0.2 \mathrm{~W} / \mathrm{m}^{2}$ & Exposure limit in Russia, Bulgaria \\
\hline $0.1 \mathrm{~W} / \mathrm{m}^{2}$ & Exposure limit in Poland, Paris, Hungary \\
\hline $0.1 \mathrm{~W} / \mathrm{m}^{2}$ & Exposure limit in Italy in sensitive areas \\
\hline $0.095 \mathrm{~W} / \mathrm{m}^{2}$ & Exposure limit in Switzerland \\
\hline $0.09 \mathrm{~W} / \mathrm{m}^{2}$ & $\begin{array}{l}\text { ECOLOG 1998 (Germany) Precaution } \\
\text { recommendation only }\end{array}$ \\
\hline $0.001 \mathrm{~W} / \mathrm{m}^{2}$ & Exposure limit in Austria \\
\hline
\end{tabular}

Table1.1 Revised EMF radiation norms for mobile towers (BTS) in India.

\begin{tabular}{|c|c|c|}
\hline Frequency & $\begin{array}{c}\text { ICNIRP } \\
\text { Radiation } \\
\text { norms }\end{array}$ & $\begin{array}{c}\text { Revised DoT Norms } \\
\text { effective from } \\
\text { September 2012 }\end{array}$ \\
\hline $900.0 \mathrm{MHz}$ & $4.5 \mathrm{~W} / \mathrm{m}^{2}$ & $0.450 \mathrm{~W} / \mathrm{m}^{2}$ \\
\hline $1800.0 \mathrm{MHz}$ & $9.0 \mathrm{~W} / \mathrm{m}^{2}$ & $0.90 \mathrm{~W} / \mathrm{m}^{2}$ \\
\hline $2100.0 \mathrm{MHz}$ & $10.5 \mathrm{~W} / \mathrm{m}^{2}$ & $1.050 \mathrm{~W} / \mathrm{m}^{2}$ \\
\hline
\end{tabular}

Another restriction in the EMF exposure is on the antennas, that is how many cellular antennas one can install on the cellular base station tower [10]. Table 1.2 gives the information regarding number of antennas and the safe distance. Distance between dwellings and base station antennas changes according to number of antennas mounted on the base station tower.

Table1.2 Safe distance in case of multiple antennas

\begin{tabular}{|c|c|c|}
\hline S.No. & $\begin{array}{c}\text { Number of } \\
\text { Multiple } \\
\text { Antennas on a tower }\end{array}$ & $\begin{array}{c}\text { Safe Distance (in } \\
\text { meters) }\end{array}$ \\
\hline 1 & 2 & 35 \\
\hline 2 & 4 & 45 \\
\hline 3 & 6 & 55 \\
\hline
\end{tabular}

\section{RESULTS}

The measurements of power densities were performed at 5 places in Kolhapur city in India and around 15 cellular mobile base stations.
Table 1.3 shows the measured power density and electric field intensity at base station site; population density was higher around the base station. It is found that up to $120 \mathrm{~m}$ the power density was increased and then it was decreased, this base station comes under LOS. Here maximum average power density and maximum power density were $25550 \mu \mathrm{w} / \mathrm{m}^{2}$ and $40380 \mu \mathrm{w} / \mathrm{m}^{2}$. The maximum average electric field intensity found was $2857 \mathrm{mv} / \mathrm{m}$.

Table 1.3 Measured data at base station

\begin{tabular}{|l|c|c|c|c|}
\hline $\begin{array}{c}\text { Distance } \\
(\mathbf{m})\end{array}$ & $\begin{array}{c}\text { Avg. } \\
\text { power } \\
\mathbf{d e n s i t y} \\
\boldsymbol{\mu w} / \mathbf{~ m}^{2}\end{array}$ & $\begin{array}{c}\text { Avg. } \\
\text { Electric } \\
\text { field } \\
\mathbf{m v} / \mathbf{m}\end{array}$ & $\begin{array}{c}\text { Max. } \\
\text { Avg. } \\
\text { power } \\
\mathbf{d e n s i t y} \\
\boldsymbol{\mu w} / \mathbf{m}^{2}\end{array}$ & $\begin{array}{c}\text { Max. } \\
\text { power } \\
\mathbf{d e n s i t y} \\
\boldsymbol{\mu w} / \mathbf{~ m}^{2}\end{array}$ \\
\hline 10 & 2770 & 1470.4 & 5556 & 6174 \\
\hline 20 & 2905 & 1245.4 & 32340 & 34340 \\
\hline 30 & 2110 & 1401 & 4359 & 4421 \\
\hline 40 & 2485 & 1185.1 & 32340 & 34340 \\
\hline 50 & 1785.8 & 1167 & 32340 & 34340 \\
\hline 60 & 3168 & 1306.3 & 32340 & 34340 \\
\hline 70 & 2305 & 1226.6 & 32340 & 34340 \\
\hline 80 & 2346 & 1300.4 & 32340 & 34340 \\
\hline 90 & 3038 & 1384.9 & 32340 & 34340 \\
\hline 100 & 6026 & 2194 & 32340 & 34340 \\
\hline 110 & 12470 & 2267 & 32340 & 34340 \\
\hline 120 & 10018 & 2428 & 32340 & 34340 \\
\hline 130 & 4175 & 2465 & 32340 & 34340 \\
\hline 140 & 18430 & 3878 & 32340 & 34340 \\
\hline 150 & 20170 & 3166 & 32340 & 34340 \\
\hline
\end{tabular}

From table 2.0 from graph it is found that the maximum power density was $34.34 \mathrm{mw} / \mathrm{m}^{2}$, maximum average power density was $32.34 \mathrm{mw} / \mathrm{m}^{2}$ and average power density was $20.17 \mathrm{mw} / \mathrm{m}^{2}$.

Figure 2 . shows daily variations in the average power density from base station. The variation in power density is from 120 $\mu \mathrm{w} / \mathrm{m}^{2}$ to $520 \mu \mathrm{w} / \mathrm{m}^{2}$.

Figure 3. shows daily variations in the electromagnetic field exposure from base station. The variation in electric field is from $100 \mathbf{~ m v} / \mathbf{m}$ to $500 \mathbf{~ m v} / \mathbf{m}$.

It was found that power densities varied both in space and time. Large fluctuations in the readings were observed at every site and for every measurement. There were large discrepancies between the maximum and the minimum values at every base station site. 


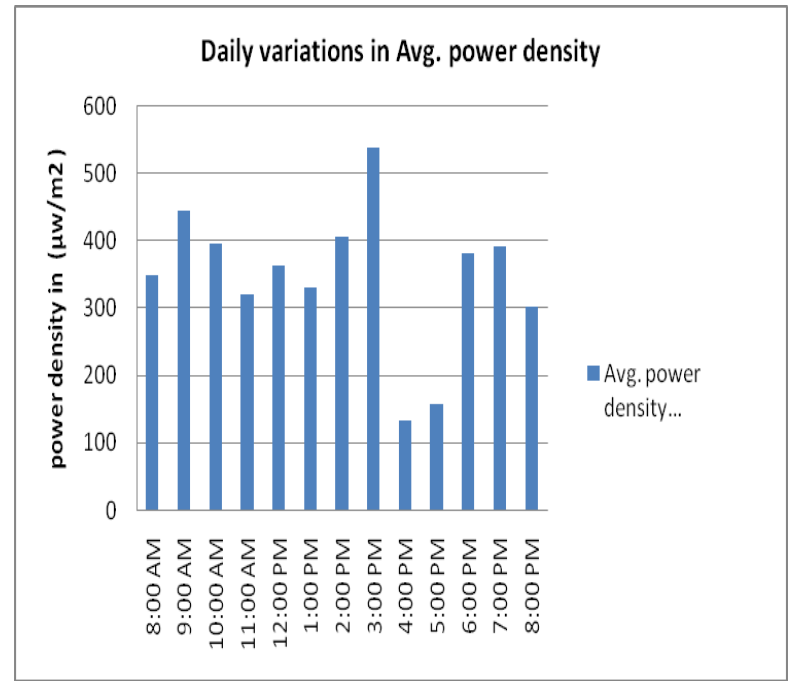

Figure 2.0 Daily variations in power density

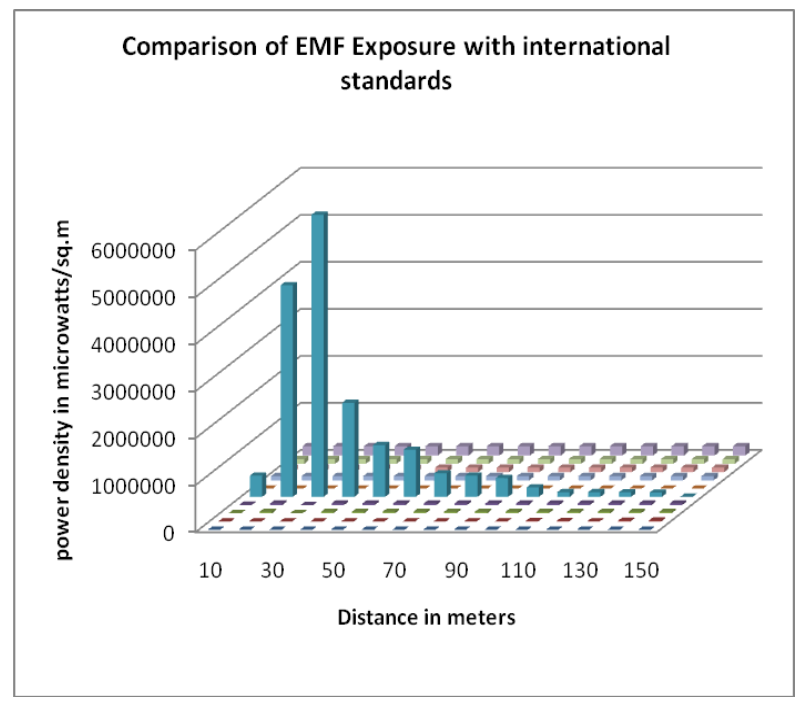

Figure 3. Comparison of EMF exposure reference levels

The power density of base station transmitting antenna sites increases up to 100 meters and then it decreases as shown in figure 1.0. The maximum power density measured was 51.36 $\mathrm{mw} / \mathrm{m}^{2}$ and electric field intensity measured was $18.905 \mathrm{v} / \mathrm{m}$. Power density and electric field were measured in the transmitting direction of the base station. In case of LOS the EMF exposure increases up to 100 meters but in case of NLOS it increases up to 50 to 80 meters. There were more variations in the daily EMF exposure, to observe these variations power density and electric field were measured from 8 am to $8 \mathrm{pm}$ as in figure 2 .

In figure 4. The comparison of power density levels with standard reference levels set by different countries is elaborated. In most of the cases the measured field exposure is well below the reference level. But in one of the case it is above the reference level.

\section{CONCLUSION}

After measuring the electromagnetic field exposure in the surrounding area of cellular base stations it is found that electromagnetic field exposure was increasing up to 100 meters in case of LOS and decreases after 110 meters. In case of NLOS electromagnetic field exposure increases up to 70 meters and then decreases.

This measured data is useful to control the radiation from base stations. One can extend this work to study the undesirable health effects due to the RF radiation from base stations as future work. Also the measured data can be analyzed by using advanced EMF exposure software such as EM CUBE, Field view and FEKO.

Electromagnetic field exposure around base station was fluctuating all the time. The maximum, average maximum and average power densities were $40.38 \mathrm{~mW} / \mathrm{m}^{2}, 25.55 \mathrm{~mW} / \mathrm{m}^{2}$ and $19.97 \mathrm{~mW} / \mathrm{m}^{2}$. Maximum electric field exposure was $2.857 \mathrm{v} / \mathrm{m}$. All measured values were well below the threshold level set by ICNIRP.

\section{ACKNOWLEDGMENTS}

Authors would like to thank Department of Technology for their cooperation for allowing us for using their labs and other facilities.

\section{REFERENCES}

[1] International Commission for Non-Ionizing Radiation Protection (ICNIRP). Guidelines for limiting exposure to time-varying electric, magnetic and electromagnetic fields (up to $300 \mathrm{GHz}$ ). Health Phys. 74, 494-522 (1998).

[2] Institute of Electrical and Electronics Engineers (IEEE). Safety levels with respect to human exposure to radio frequency electromagnetic fields, $3 \mathrm{kHz}$ to $300 \mathrm{GHz}$. Report IEEE C95.1-1991 (Piscataway, NJ) (1992).

[3] Institute of Electrical and Electronics Engineers Standards Coordinating Committee 28. Non-ionizing radiation hazards: standard for safe levels with respect to human exposure to radio frequency electromagnetic fields, $3 \mathrm{kHz}$ to $300 \mathrm{GHz}$. (ANSI/IEEE, 1999) (IEEE, NY) (1992).

[4] International Commission for Non-Ionizing Radiation Protection. Health issues related to the use of hand-held radiotelephones and base transmitters. Health Phys. 70, 587-593 (1996).

[5] National Radiation Protection Board. Board statement on restrictions on human exposure to static and time varying electromagnetic fields. NRPB Report 4(5) (Chilton, UK: NRPB) (1993).

[6] National Council on Radiation Protection and Measurements. Biological effects and exposure criteria for radio frequency electromagnetic fields. NCRP Report 86 (Bethesda, MD: NCRP) (1986).

[7] CENELEC standard EN 50383, "Basic standard for calculation and measurement of electromagnetic field strength and SAR related to human exposure from radio base stations and fixed terminal stations for wireless telecommunications system" $(110 \mathrm{MHz}-40 \mathrm{GHz})$, CENELEC standard EN 50383, 2002.

[8] RADIATION PROTECTION STANDARD "Maximum Exposure Levels to Radiofrequency Fields $-3 \mathrm{kHz}$ to 300 GHz" Radiation Protection Series Publication No. 3 ARPANSA. 
[9] Federal Communication Committee. Radio Frequency Safety OET-RF Safety FAQ's. Available at http://ftp.fcc.gov/oet/rfsafety/rf-faqs.html

[10] Cooper, J., Marx, B., Buhl, J. and Hombach, V. Determination of safety distance limits for a human near a cellular base station antenna, adopting the IEEE standard or ICNIRP guidelines. Biolelectromangetics 23 , 429-443 (2002).

[11] Byung Chan Kim, Jae-Hoon Yun, and Seong-Ook Park,Member, IEEE "Uncertainty Estimation for Evaluating Human Exposure Levels to RF Electromagnetic Fields from Cellular Base Stations" IEEE TRANSACTIONS ON ELECTROMAGNETIC COMPATIBILITY, VOL. 54, NO. 2, APRIL 2012.

[12] Bernardi, P., Cavagnaro, M., Pisa, S. and Piuzzi, E. Exposure to radio base-station antennas in urban environment.IEEE Trans. Microwave Theory Tech. 48(11) (2000).

[13] Mann, S. M., Cooper, T. G., Allen, S. G., Blackwell, R. $\mathrm{P}$. and Lowe, A. J. Exposure to radio waves near mobile phone base stations. NRPB Report 321 (Didcot: National Radiological Protection Board) (2000).

[14] Mohd Yusof Mohd Ali, Rozaimah Abd Rahim,Mohd Anuar Abd Majid and Mohd Amirul Nizam. Radiofrequency and microwave radiation safety assessment of mobile telephone base stations in Malaysia. In: Proceedings of International Conference on Non-ionizing Radiation. 20-22 October 2003, (Kuala Lumpur: UNITEN) (2003).
[15] Mobile phones and their transmitter base stations. The evidence for health hazards. A local Government and Community Resources Document. EMF acts Information Service pp. 240 (1996).

[16] Santini, R., Santini, P., Danze, J. M., Ruz, P. L. and Seigne, M. Study of the health of people living in the vicinity of mobile phone base stations: I. Influences of distance and sex. Pathol. Biol. 50, 369-373 (2002).

[17] Nararro, E. A., Segura, J., Gomez-Perretta, C., Portoles, M., Maestu, C. and Bardasano, J. L. Exposure from cellular phone base stations: a first approach. In: Proceedings of Second International Workshop on Biological Effects of EMFs, Rhode, Greece: University of Ioannina, 7-11 October (2002).

[18] Hutter, H.-P., Moshammer, H. and Kundi, M. Mobile telephone base stations: effects on health and wellbeing. In: Proceedings of the Second International Workshop on Biological Effects of EMFs, Rhode, Greece: University of Ioannina, 7-11 October (2002).

[19] Lai, H. Neurological effects of radiofrequency electromagnetic radiation. Workshop on Possible Biological and Health Effects of RF Electromagnetic Fields: Mobile Phones and Health Symposium, University of Vienna, Austria, 25-28 October (1998).

[20] Amar Renke, Mahesh Chavan A Review on RF Field Exposure from Cellular Base Stations international Journal of Computer Applications Vol. 104 Issue 12, 2014 pp 09-16. 